\title{
Developing a fuzzy ANP model for performance appraisal based on firm strategy
}

\author{
Seid Mohammad Reza Mirahmadi ${ }^{\mathbf{a}^{*}}$, Ali Attafar ${ }^{\mathrm{a}}$ and Saideh Ketabi ${ }^{\mathrm{a}}$
}

${ }^{a}$ Department of Management, University of Isfahan, Isfahan, Iran

\begin{tabular}{l}
\hline C H R O N I C L E \\
\hline Article history: \\
Received March 16, 2017 \\
Received in revised format: \\
August 20, 2017 \\
Accepted September 10, 2017 \\
Available online \\
September 10, 2017 \\
\hline Keywords: \\
Fuzzy Analytic Network Process \\
Performance Appraisal \\
Porter Competitive Strategies \\
Strategic Human Resource \\
Management \\
\end{tabular}

\section{A B S T R A C T}

\begin{abstract}
The purpose of this study is to develop a fuzzy Analytic Network Process (ANP) model that has the ability to evaluate employee performance in different strategies. A team of experts in the field of strategic human resource management and senior management of an organization engaged in steel production were involved in the study. The data collection tool was a questionnaire that was designed based on the criteria of organization's performance appraisal system. The results showed that in cost leadership strategy, compliance of work hierarchy, quantity of work and the ability to make important decisions constituted the highest coefficients, while in the focus strategy, participate in group work, power of supervision and administration and decision making ability had the highest importance. In differentiation strategy, innovation and creativity, quality and offering constructive suggestions received higher ratings than other criteria. Finally, the developed model was used to evaluate the performance of a sample employee.
\end{abstract}

(C) 2018 Growing Science Ltd. All rights reserved.

\section{Introduction}

Performance evaluation is one of the main tasks of any organization, which was performed in the past often using financial criteria. On the other hand, as organizations become larger, they need more control. The basic issue today in many organizations with different branches is that no valid and logical performance evaluation method has been proposed for them (Soltannezhad Dizaji et al. 2018). Human Resource managers frequently lead performance appraisals in their organizations, hoping to provide a variety of benefits such as improved performance, creating an opportunity for superior-subordinate communication, data for personnel decisions, etc. (Coens \& Jenkins, 2000).

The objective of personnel performance are: (1) objective on management, for example, to encourage the director to observe the subordinates' performance more carefully to become a better director of work; to provide the information about personal raises, promotion, assignment, training and retirement and to provide document description to the subordinates who may take legal actions. (2) Objective on development, for example, to recompense the subordinates' performance to encourage them; to provide

* Corresponding author. Tel: +98-913-359-4959

E-mail address: m.mirahmadi@gmail.com (S.M. R. Mirahmadi)

(c) 2018 Growing Science Ltd. All rights reserved. doi: $10.5267 /$ j.ds1.2017.9.001 
the information about how to improve the working performance; to provide the subordinates with the opportunity to show their expectations, attempts, satisfaction or dissatisfaction about the works; to develop the potential of organization members and program of personal career. (3) Objective on research, for example, to estimate the effect of training and selection; to provide relative information about human resource research (chang et al., 2004).

To bring the objectives of performance appraisal into full play, the selection of performance index is very important, because whether the index is chosen properly or not concern whether the performance of the appraised can be estimated objectively and comprehensively, and a set of highly reliable and effective performance appraisal rules and model, not only enhances the reasonability and objectivity of the performance appraisal, but also promotes the personnel's morale, to obtain the maximum management effect.

This paper introduces a methodology that uses 'fuzzy set theory' and 'analytic network process technique' for multi-criteria evaluation of performance based on firm's competitive strategy. The methodology makes it possible to rank the performance of employees evaluated by multiple criteria.

The remainder of this paper is organized as follows. In Section 2, we describe the Strategy based performance appraisal system. A fuzzy ANP based approach is proposed in Section 3, followed by the performance appraisal and ranking model in Section 4. A case study is given in Section 5, and conclusions are presented in Section 6.

\section{Strategy based performance appraisal system}

Strategic human resource management (SHRM) is a strategic approach to manage human resources of an organization. Compared with technical HRM, SHRM is considered a relatively 'new' concept, despite its continuous development over the past two decades. The traditional HRM function, or technical HRM activities, covers a wide range of employment practices, including recruitment, selection, performance appraisal, training and development and the administration of compensation and benefits. By combining the HRM function with business strategy, SHRM reflects a more flexible arrangement and utilization of human resources to achieve the organizational goals, and accordingly helps organizations gain a competitive advantage (Wei \& Lau, 2005; Sadatrasool et al., 2016).

The congruence or 'fit' between HR practice and business strategy has been emphasized in studies related to SHRM (Miles \& Snow, 1984; Baird \& Meshoulam, 1988; Wright \& McMahan, 1992). It is the primary logic of melding the HR function into the strategy of a firm. A great deal of conceptual illustrations assert that the employment of effective HR practices and the design of a HR system compatible with the firm strategy are imperative for the successful implementation of business strategies (e.g., Lengnick-Hall \& Lengnick-Hall, 1988; Sadi-Nezhad, 2017).

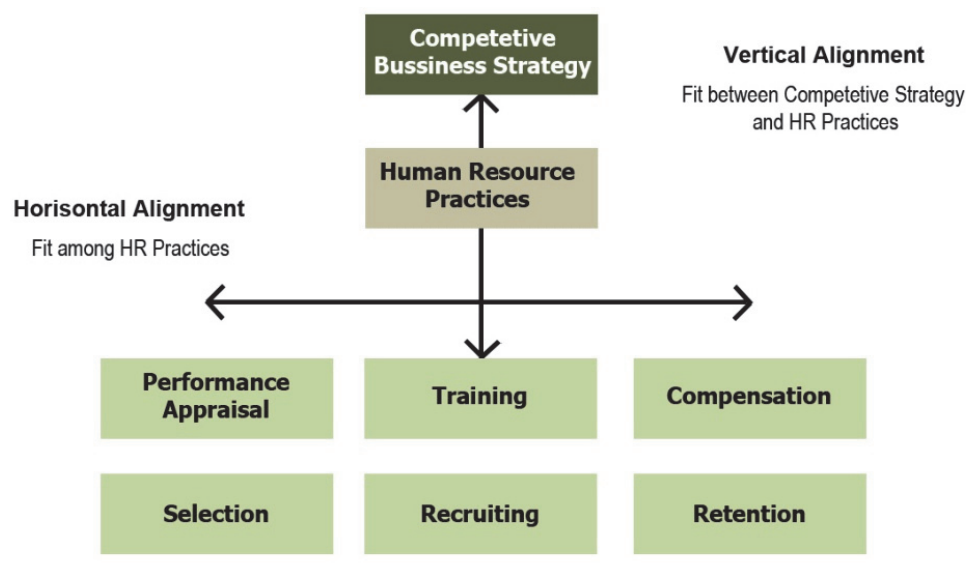

Fig. 1. Vertical and Horizontal Alignment

Performance appraisal system plays an important role in strategic human resource management. In the 
context of increasing demands for productivity, the required implementation of transparent employee evaluation systems constitutes a challenge and an opportunity for firms for aligning the activity of their human resources with their strategies. However, despite the growing interest in the performance appraisal of employee, only a few reported studies propose models that cover the alignment between firm's strategy and performance appraisal system.

Effectively evaluating employees and communicating feedback to them is a constant challenge in organizational life. Generally speaking, a performance appraisal is an evaluation of an employee's performance along pertinent dimensions (e.g., results, participation, etc.), and feedback is the communication of the appraisal results to the person being appraised. Performance appraisals are essential because they often influence vital issues such as the focus of individual improvement, pay raises, promotions, and work assignment (Butler et al., 1991; Druskat \& WolV, 1999; Ouchi, 1981; Staw, 1980; Sandhya \& Garg, 2016; Anyaeche et al., 2017).

\subsection{Competitive strategy}

The strategy field presents various typologies to describe the generic competitive strategies of firms, how firms compete in specific businesses or industries by exploiting their competitive advantages in order to realize their goals (Hambrick, 1983; Miles \& Snow, 1978; Porter, 1980). The typologies all focus on a firm's relative emphasis on operational efficiency and low cost or uniqueness in the market. We focus on Porter's (1980) typology of generic competitive strategies which is made up of overall cost leadership, differentiation and focus strategies.

\section{Fuzzy ANP}

\subsection{Analytic network process (ANP)}

The purpose of the ANP approach is to solve problems involving interdependence and feedback between criteria or alternative solutions. ANP is the general form of the analytic hierarchy process (AHP), which has been used in multi-criteria decision-making (MCDM) in order to consider nonhierarchical structures. MCDM has been applied to numerous disciplines (Huang et al., 2005).

The ANP introduced by Saaty, is a generalization of the analytic hierarchy process (AHP) (Saaty, 1996). Whereas AHP represents a framework with a uni-directional hierarchical AHP relationship, ANP allows for complex interrelationships among decision levels and attributes. The ANP feedback approach replaces hierarchies with networks in which the relationships between levels are not easily represented as higher or lower, dominant or subordinate, direct or indirect (Meade \& Sarkis, 1999). For instance, not only does the importance of the criteria determine the importance of the alternatives, as in a hierarchy, but also the importance of the alternatives may have impact on the importance of the criteria (Saaty, 1996). Therefore, a hierarchical structure with a linear top-to-bottom form is not suitable for a complex system.

AHP is a comprehensive framework that is designed to cope with the intuitive, the rational, and the irrational when we make multi-objective, multi-criterion, and multi-actor decisions, with or without certainty for any number of alternatives. The basic assumptions of AHP are that it can be used in functional independence of an upper part or cluster of the hierarchy from all its lower parts and the criteria or items in each level (Meade \& Sarkis, 1999).

Many decision-making problems cannot be structured hierarchically because they involve the interaction and dependence of higher level elements on lower level elements (Saaty \& Takizawa, 1986; Saaty, 1996). Structuring a problem involving functional dependence allows for feedback among clusters. This is a network system. Saaty (1996) suggested the use of AHP to solve the problem of independence on alternatives or criteria, and the use of ANP to solve the problem of dependence among alternatives or criteria.

The major difference between AHP and ANP is that ANP is capable of handling interrelationships between the decision levels and attributes by obtaining the composite weights through the development of a "supermatrix" (Shyur, 2006). The supermatrix is actually a partitioned matrix, where each matrix segment represents a relationship between two components or clusters in a system (Saaty, 1996). 
The process of ANP involves three substeps and shown as follows (Shyur, 2006):

Step 1: Without assuming the interdependence among criteria, the decision-makers are asked to evaluate all proposed criteria pairwise. They respond questions such as: "which criteria should be emphasized more in a personnel, and how much more?" The responses were presented numerically and scaled on the basis of Saaty's 1-9 scale (Table 1). Each pair of criteria is judged only once. A reciprocal value is automatically assigned to the reverse comparison. Once the pairwise comparisons are completed, the local weight vector $\mathrm{w}_{1}$ is computed as the unique solution to

$\mathrm{Aw}_{1}=\lambda_{\max } \mathrm{w}_{1}$,

where $\lambda_{\max }$ is the largest eigenvalue of pairwise comparison matrix $A$. The obtained vector is further normalized by dividing each value by its column total to represent the normalized local weight vector $\mathrm{w}_{2}$.

Step 2: Next to resolve the effects of the interdependence that exists between the evaluation criteria. The decision-makers examine the impacts of all the criteria on each other by using pairwise comparisons as well. Questions such as: "which criterion will influence criterion 1 more: criterion 2 or criterion 3? and how much more?" are answered. Various pairwise comparison matrices are formed for each of the criterion. These pairwise comparison matrices are needed to identify the relative impacts of criteria interdependent relationships. The normalized principal eigenvectors for these matrices are calculated and shown as column component in interdependence weight matrix of criteria B, where zeros are assigned to the eigenvector weights of the criteria from which a given criterion is given.

Step 3: Now we can obtain the interdependence weights of the criteria by synthesizing the results from previous two steps as follows:

$\mathrm{w}_{\mathrm{c}}=\mathrm{Bw}_{2}^{\mathrm{T}}$.

3.2 Fuzzy set theory

Fuzzy set theory was first developed by Zadeh (1965) when he was attempting to solve fuzzy phenomenon problems, including problems with uncertain, incomplete, unspecific, or fuzzy situations. Fuzzy set theory is more advantageous than traditional set theory when describing set concepts in human language. It allows us to address unspecific and fuzzy characteristics by using a membership function that partitions a fuzzy set into subsets of members that "incompletely belong to" or "incompletely do not belong to" a given subset (Chen \& Chen, 2010). This theory provides a different way to view the problem of modeling uncertainty and offers a wide range of computational tools to aid decision making (Karmaker \& Saha, 2015).

A major contribution of fuzzy set theory is its capability of representing vague data. The theory also allows mathematical operators and programming apply to the fuzzy domain. A fuzzy set is a class of objects with a continuum of grades of membership. Such a set is characterized by a membership (characteristic) function, which assigns to each object a grade of membership ranging between zero and one (Kahraman et al., 2003).

\subsection{Fuzzy number and Fuzzy linguistic variable}

We order the universe of discourse such that $U$ is a collection of targets, where each target in the universe of discourse is called an element. A fuzzy number $\tilde{A}$ is mapped onto $U$ such that a random $\mathrm{x} \rightarrow \mathrm{U}$ is appointed a real number, $\mu_{\tilde{\mathrm{A}}}(\mathrm{x}) \rightarrow[0,1]$. If another element in $\mathrm{U}$ is greater than $\mathrm{x}$, we call that element under $\mathrm{A}$.

The universe of real numbers $R$ is a triangular fuzzy number, $\tilde{A}$, which means that for $x \in R, \mu_{\tilde{A}}(x) \in$ $[0,1]$ and

$\mu_{\tilde{A}}(x)=\left\{\begin{array}{cc}(x-L) /(M-L), & L \leq x \leq M, \\ (U-x) /(U-M), & M \leq x \leq U, \\ 0, & \text { otherwise, }\end{array}\right.$ 
Note that $\tilde{A}=(L, M, U)$, where $L$ and $U$ represent fuzzy probability between the lower and upper boundaries, respectively, as in Fig. 2.

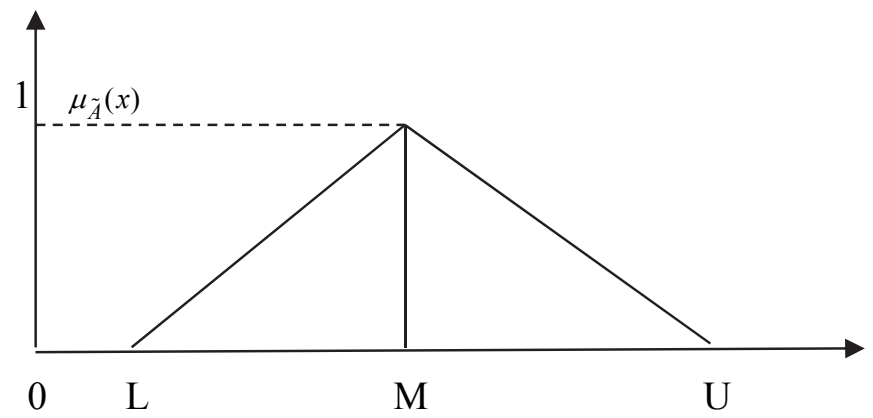

Fig. 2. Triangular fuzzy number (Chen \& Chen, 2010)

Assume two fuzzy numbers $\tilde{A}_{1}=\left(L_{1}, M_{1}, U_{1}\right)$ and $\tilde{A}_{1}=\left(L_{2}, M_{2}, U_{2}\right)$; then:

(1) $\tilde{A}_{1} \oplus \tilde{A}_{2}=\left(L_{1}, M_{1}, U_{1}\right) \oplus\left(L_{2}, M_{2}, U_{2}\right)=\left(L_{1}+L_{2}, M_{1}+M_{2}, U_{1}+U_{2}\right)$

(2) $\tilde{A}_{1} \otimes \tilde{A}_{2}=\left(L_{1}, M_{1}, U_{1}\right) \otimes\left(L_{2}, M_{2}, U_{2}\right)=\left(L_{1} L_{2}, M_{1} M_{2}, U_{1} U_{2}\right), L_{i}>0, M_{i}>0, U_{i}>0$

(3) $\tilde{A}_{1}-\tilde{A}_{2}=\left(L_{1}, M_{1}, U_{1}\right)-\left(L_{2}, M_{2}, U_{2}\right)=\left(L_{1}-L_{2}, M_{1}-M_{2}, U_{1}-U_{2}\right)$

(2) $\tilde{A}_{1} \div \tilde{A}_{2}=\left(L_{1}, M_{1}, U_{1}\right) \div\left(L_{2}, M_{2}, U_{2}\right)=\left(L_{1} / U_{2}, M_{1} / M_{2}, U_{1} / L_{2}\right), L_{i}>0, M_{i}>0, U_{i}>0$

$\tilde{\mathrm{A}}_{1}^{-1}=\left(\mathrm{L}_{1}, \mathrm{M}_{1}, \mathrm{U}_{1}\right)^{-1}=\left(1 / \mathrm{U}_{1}, 1 / \mathrm{M}_{1}, 1 / \mathrm{L}_{1}\right), \mathrm{L}_{\mathrm{i}}>0, \mathrm{M}_{\mathrm{i}}>0, \mathrm{U}_{\mathrm{i}}>0$

The fuzzy linguistic variable is a variable that reflects different aspects of human language. Its value represents the range from natural to artificial language. When the values or meanings of a linguistic factor are being reflected, the resulting variable must also reflect appropriate modes of change for that linguistic factor. Moreover, variables describing a human word or sentence can be divided into numerous linguistic criteria, such as equally important, moderately important, strongly important, very strongly important, and extremely important, as shown in Fig. 3; definitions and descriptions are shown in Table 1. For the purposes of the present study, the 6-point scale (just equal, equally important, moderately important, strongly important, very strongly important and extremely important) proposed by Kahraman et al. (2006) is used.

\section{Table 1}

Linguistic scales for importance (Kahraman et al., 2006)

\begin{tabular}{lll}
\hline Linguistic scale for importance & Triangular fuzzy scale & Triangular fuzzy reciprocal scale \\
\hline Just equal & $(1,1,1)$ & $(1,1,1)$ \\
Equally important (EI) & $(1 / 2,1,3 / 2)$ & $(2 / 3,1,2)$ \\
Weakly more important (WMI) & $(1,3 / 2,2)$ & $(1 / 2,2 / 3,1)$ \\
Strongly more important (SMI) & $(3 / 2,2,5 / 2)$ & $(2 / 5,1 / 2,2 / 3)$ \\
Very strongly more important (VSMI) & $(2,5 / 2,3)$ & $(1 / 3,2 / 5,1 / 2)$ \\
Absolutely more important (AMI) & $(5 / 2,3,7 / 2)$ & $(2 / 7,1 / 3,2 / 5)$ \\
\hline
\end{tabular}

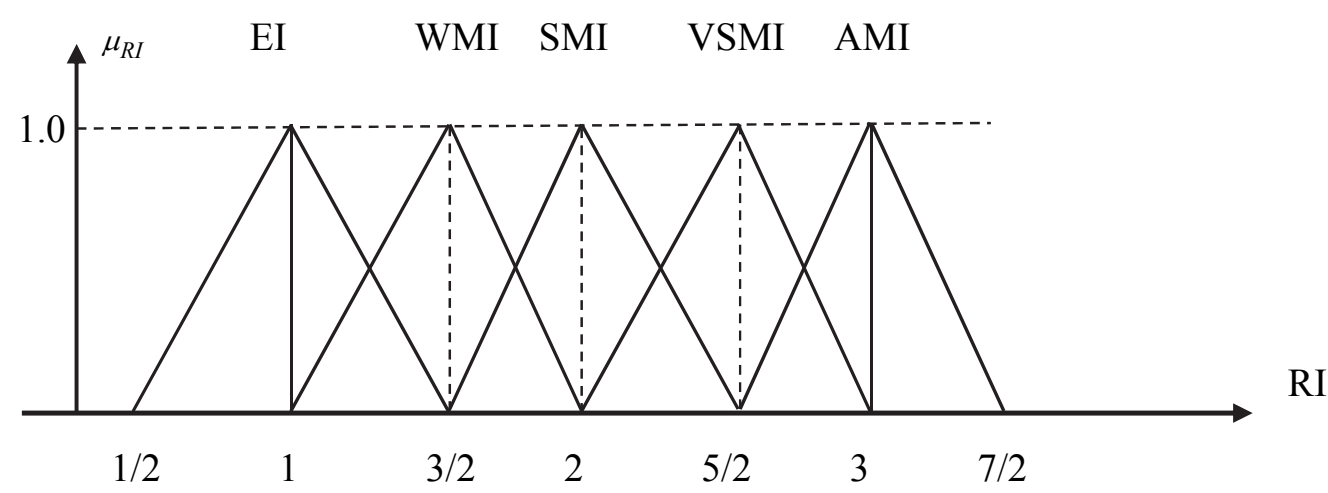

Fig. 3. Linguistic scale for relative importance (Kahraman et al., 2006) 


\subsection{Fuzzy analytic hierarchy process}

There are many fuzzy AHP methods proposed by various authors (Buckley, 1985; Chang, 1992, 1996; Cheng, 1997; Deng, 1999; Leung \& Cao, 2000; Mikhailov, 2004; Van Laarhoven \& Pedrycz, 1983). These methods are systematic approaches to the alternative selection and justification problem by using the concepts of fuzzy set theory and hierarchical structure analysis. Decision makers usually find that it is more confident to give interval judgments than fixed value judgments. This is because usually he/she is unable to explicit about his/her preferences due to the fuzzy nature of the comparison process (Yüksel \& Dağdeviren, 2010).

In this study, we prefer Chang $(1992,1996)$ extent analysis method because the steps of this approach are easier than the other fuzzy AHP approaches. The steps of Chang $(1992,1996)$ extent analysis approach are as follows:

Let $X=\left\{x_{1}, x_{2}, \ldots, x_{n}\right\} \quad$ be an object set, and $U=\left\{u_{1}, u_{2}, \ldots, u_{n}\right\}$ be a goal set. According to the method of Chang (1992) extent analysis, each object is taken and extent analysis for each goal, $\mathrm{g}_{\mathrm{i}}$, is performed, respectively. Therefore, $m$ extent analysis values for each object can be obtained, with the following signs:

$M_{g_{i}}^{1}, M_{g_{i}}^{2}, \ldots, M_{g_{i}}^{n}, \quad i=1,2, \ldots, n$,

where all the $\mathrm{M}_{\mathrm{g}_{\mathrm{i}}}^{\mathrm{j}}(\mathrm{j}=1,2, \ldots, \mathrm{m})$ are triangular fuzzy numbers. The steps of Chang's extent analysis can be given as in the following:

Step 1: The value of fuzzy synthetic extent with respect to the ith object is defined as

$S_{i}=\sum_{j=1}^{m} M_{g_{i}}^{j} \otimes\left[\sum_{i=1}^{n} \sum_{j=1}^{m} M_{g_{i}}^{j}\right]^{-1}$.

To obtain $\sum_{j=1}^{m} M_{g_{i}}^{j}$, perform the fuzzy addition operation of extent analysis values for a particular matrix such that

$\sum_{j=1}^{m} M_{g_{i}}^{j}=\left(\sum_{j=1}^{m} l_{j}, \sum_{j=1}^{m} m_{j}, \sum_{j=1}^{m} u_{j}\right)$.

And to obtain $\sum_{\mathrm{i}=1}^{\mathrm{n}} \sum_{\mathrm{j}=1}^{\mathrm{m}} \mathrm{M}_{\mathrm{g}_{\mathrm{i}}}^{\mathrm{j}}$ perform the fuzzy addition operation of $\mathrm{M}_{\mathrm{g}_{\mathrm{i}}}^{\mathrm{j}}(\mathrm{j}=1,2, \ldots, \mathrm{m})$ values such that

$\sum_{i=1}^{n} \sum_{j=1}^{m} M_{g_{i}}^{j}=\left(\sum_{i=1}^{n} l_{j}, \sum_{i=1}^{n} m_{j}, \sum_{i=1}^{n} u_{j}\right)$

And then compute the inverse of the vector in equation above such that

$\left[\sum_{i=1}^{n} \sum_{j=1}^{m} M_{g_{i}}^{j}\right]^{-1}=\left(\frac{1}{\sum_{i=1}^{n} u_{j}}, \frac{1}{\sum_{i=1}^{n} m_{j}}, \frac{1}{\sum_{i=1}^{n} l_{j}}\right)$.

Step 2: The degree of possibility of $M_{2}=\left(L_{2}, M_{2}, U_{2}\right) \geq M_{2}=\left(L_{1}, M_{1}, U_{1}\right)$ is defined as

$\mathrm{V}\left(\mathrm{M}_{2} \geq \mathrm{M}_{1}\right)=\sup \left[\min \left(\mu_{\mathrm{M}_{1}}(\mathrm{x}), \mu_{\mathrm{M}_{2}}(\mathrm{y})\right)\right]$

And can be equivalently expressed as follows:

$V\left(M_{2} \geq M_{1}\right)=\operatorname{hgt}\left(M_{1} \cap M_{2}\right)=\mu_{M_{2}}(d)= \begin{cases}1, & \text { if } m_{2} \geq m_{1}, \\ 0, & \text { if } l_{1} \geq u_{2}, \\ \frac{l_{1}-u_{2}}{\left(m_{2}-u_{2}\right)-\left(m_{1}-l_{1}\right)} & \text { otherwise }\end{cases}$ 
where $d$ the ordinate of the highest intersection is point $D$ between $\mu_{M_{1}}$ and $\mu_{M_{2}}$ (see Fig. 4). To compare $M_{1}$ and $M_{2}$, we need both the values of $V\left(M_{1} \geq M_{2}\right)$ and $V\left(M_{2} \geq M_{1}\right)$.

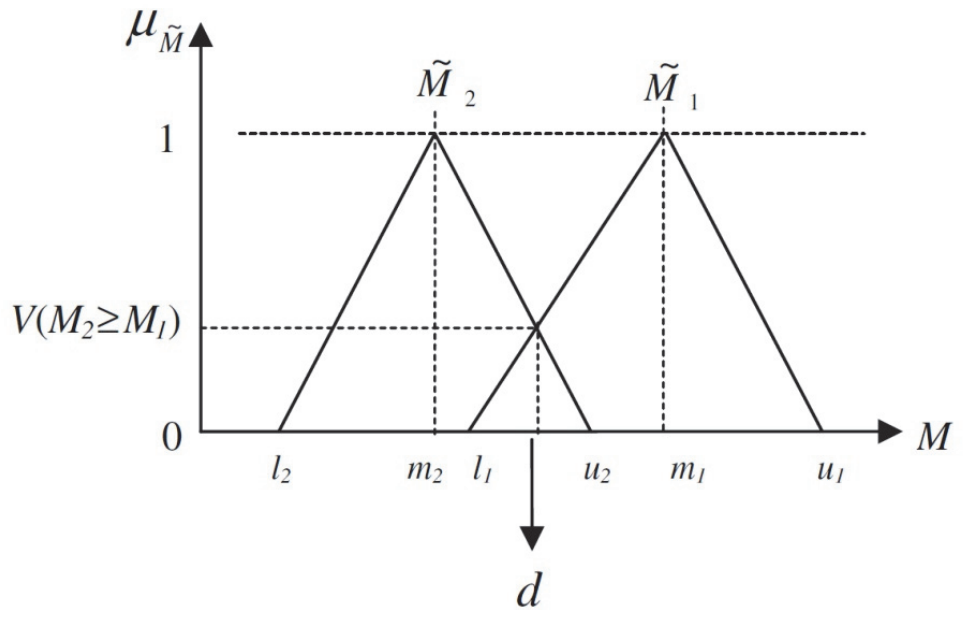

Fig. 4. The intersection between $M_{1}$ and $M_{2}$

Step 3: The degree possibility for a convex fuzzy number to be greater than $\mathrm{k}$ convex fuzzy numbers $\mathrm{M}_{\mathrm{i}}(\mathrm{i}=1,2, \ldots, \mathrm{k})$ can be defined by

$V\left(M \geq M_{1}, M_{2}, \ldots, M_{k}\right)=V\left[\left(M \geq M_{1}\right)\right.$ and $\left(M \geq M_{2}\right)$ and $\ldots$ and $\left(M \geq M_{k}\right)=\min \left(M \geq M_{i}\right), i=1,2, \ldots, k$

Assume that

$d\left(A_{i}\right)=\min V\left(S_{i} \geq S_{k}\right)$.

For $\mathrm{k}=1,2, \ldots, \mathrm{n} ; \mathrm{k} \neq \mathrm{i}$. Then the weight vector is given by

$W=\left(d\left(A_{1}\right), d\left(A_{2}\right), \ldots, d\left(A_{n}\right)\right)^{T}$

where $A_{i}(i=1,2, \ldots, n)$ are $n$ elements.

Step 4: Via normalization, the normalized weight vectors are

$W=\left(d\left(A_{1}\right), d\left(A_{2}\right), \ldots, d\left(A_{n}\right)\right)^{T}$,

where $\mathrm{W}$ is a nonfuzzy number (Chang, 1992, 1996).

\section{Proposed model}

The suggested model for the measurement of performance based on firm's strategy includes the steps as following:

Step 1: Identify the factors, sub-factors and strategies to be used in the model.

Step 2: Structure ANP model for each strategy.

Step 3: Determine the local weights of the factors and sub-factors for each strategy by using pairwise comparison matrices (assume that there is no dependence among the factors). The fuzzy scale regarding relative importance to measure the relative weights is given in Fig. 3 and Table 1. This scale is proposed by Kahraman et al. (2006) and used for solving fuzzy decision-making problems (Kahraman et al., 2006; Tolga et al., 2005) in the literature. This scale will be used in Chang (1992) fuzzy AHP approach. Step 4: Determine, with fuzzy scale (Table 1), the inner dependence matrix of each factor with respect to the other factors in each strategy. This inner dependence matrix is multiplied with the local weights of the factors, determined in Step 3, to compute the interdependent weights of the factors.

Step 5: Calculate the global weights for the sub-factors in each strategy. Global sub-factor weights are computed by multiplying local weight of the sub-factor with the interdependent weights of the factor to which it belongs.

Step 6: Determine the importance of each strategy.

Step 7: Combining ANP model for each strategy in one model.

Step 8: Measure the sub-factors for each employee. Linguistic variables proposed by Cheng, Yang, and Hwang (1999) are used in this step. The membership functions of these linguistic variables are shown in Fig. 5, and the average values related with these variables are shown in Table 2. 
Step 9: Calculate the performance of each employee by using the global sub-factor weights, linguistic values and strategy weights.

Table 2

Linguistic values and mean of fuzzy numbers (Dağdeviren \& Yüksel, 2010)

\begin{tabular}{ll}
\hline Linguistic values for sub-factors & The mean of fuzzy numbers \\
\hline Very high $(\mathrm{VH})$ & 1 \\
High $(\mathrm{H})$ & 0.75 \\
Medium $(\mathrm{M})$ & 0.5 \\
Low (L) & 0.25 \\
Very low (VL) & 0 \\
\hline
\end{tabular}

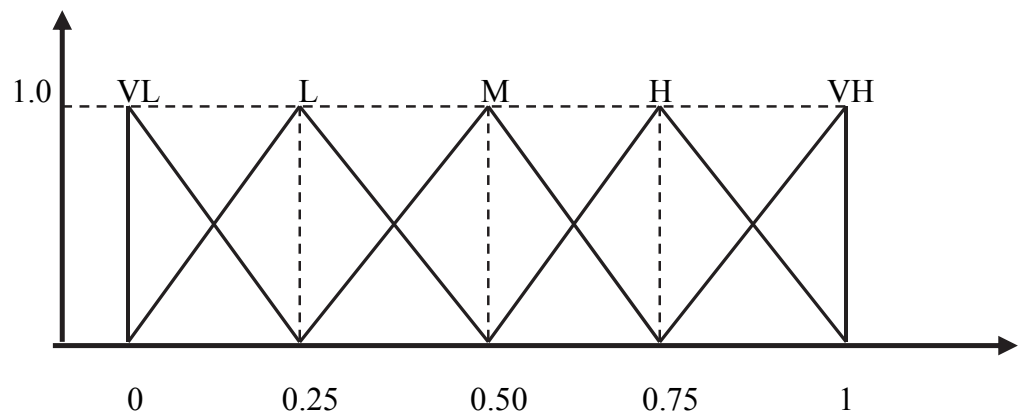

Fig. 5. Membership functions of linguistic values for sub-factor rating (Dagdeviren \& Yüksel, 2010).

\section{Empirical study of performance based performance appraisal system}

The case study for the application of fuzzy ANP model which measures personnel performance based on firm's strategy is performed in a steel manufacturing firm in Isfahan, Iran. For the application, an expert team is established from managers of the company from human resource department and the authors of this paper. The proposed ANP model is explained with applications based on the steps given in the previous section and importance of personnel performance criteria are computed by using the model:

Step 1: The factors and sub-factors used to measure the performance are determined in this step. Factors suggested by expert team were used in the study. Table 3 shows the factors and the sub-factors concerned.

Table 3

Factors and sub-factors used in the model

\begin{tabular}{ll}
\hline Factors & Sub-factors \\
\hline \multirow{3}{*}{$\begin{array}{l}\text { Personal Characteristics } \\
\text { (P) }\end{array}$} & Work Ethics (P1) \\
& Innovation and Creativity (P2) \\
& Analyzing Ability (P3) \\
& Reliability (P4) \\
& Compliance with Safety Regulations (W1) \\
Work Processes & Compliance of Work Hierarchy (W2) \\
(W) & Participate in Group Work (W3) \\
& Use of Equipment (W4) \\
& Disciplinary Regulations (W5) \\
\hline \multirow{2}{*}{$\begin{array}{l}\text { Outcomes } \\
\text { (Q) }\end{array}$} & Ability to Make Decisions (W6) \\
& Power of Supervision and Administration (W7) \\
\hline & Quantity (Q1) \\
& Quality (Q2) \\
& Efficiency (Q3) \\
& Offering Constructive Suggestions (O4) \\
\hline
\end{tabular}


Step 2: The ANP model formed by the factors and sub-factors determined in the first step is shown in Fig. 6. Hence we accept porter's typology for strategies, we develop 3 ANP model for 3 generic strategies: cost leadership, focus and differentiation strategies. Each ANP model is composed of three stages. The first step includes the objective of the model, determined as "the measurement of performance in specific strategy". The second step includes the factors to be used in the measurement of performance. The factors of second stage are connected to the goal with a single directional arrow. The arrows in the second stage represent the interdependence among the factors. The interdependencies among factors which are in this stage are taken into account and by this way the effects of the factors on each other are analyzed. Sub-factors related to the factors are in the third stage of the model and the factors determined in Step 1 are also in this stage.

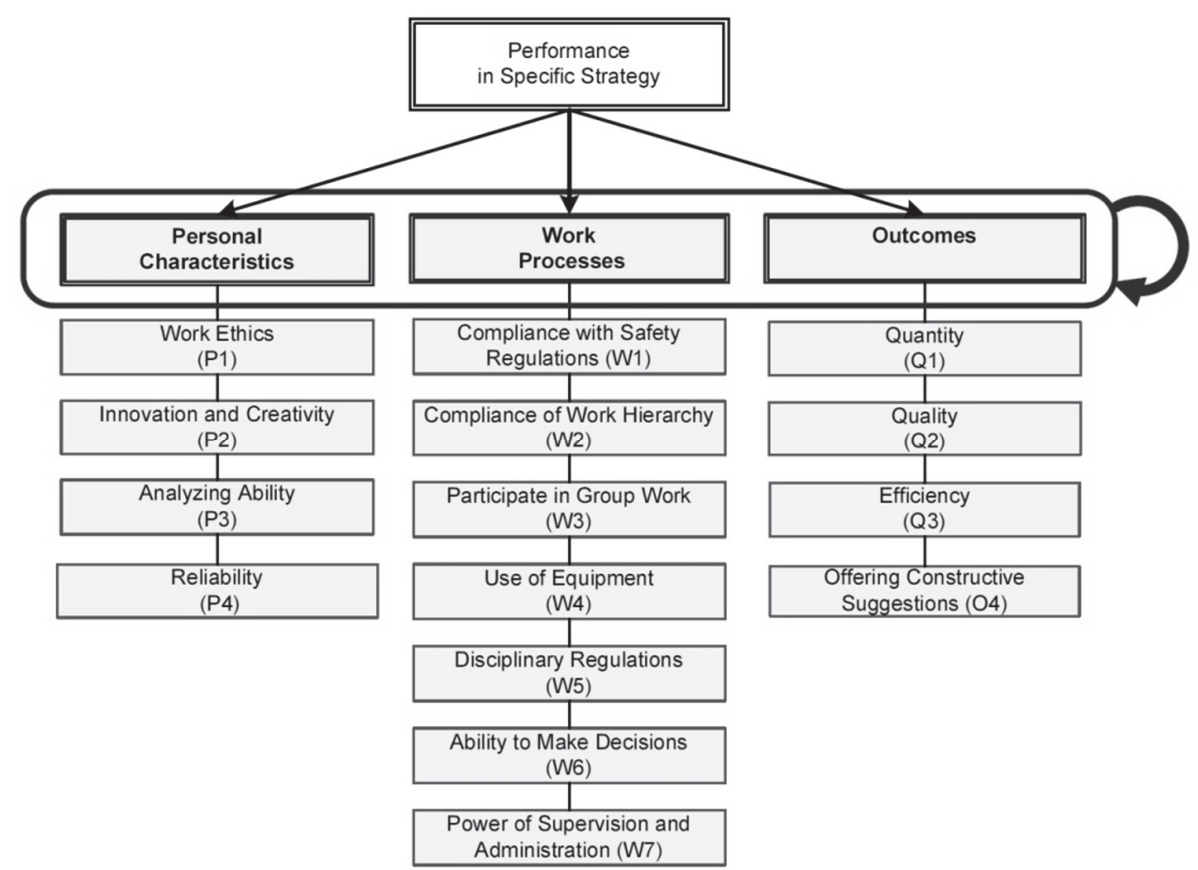

Fig. 6. The proposed ANP model for measurement of performance

Step 3: In this step, local weights of the factors and sub-factors which take part in the second and third levels of ANP model (Fig. 6), are calculated. Pairwise comparison matrices are formed by the expert team by using the scale given in Table 1. As mentioned before, for each strategy, local weights of the factors and sub-factors are calculated. For example, in const leadership strategy, personal characteristics are compared with work processes using the question "How important is personal characteristics (P) when it is compared with work processes (W) when firm select cost leadership strategy?" and the answer to this linguistic scale is placed in the relevant cell against the triangular fuzzy numbers. All the fuzzy evaluation matrices are produced in the same manner.

Step 4: In this step, interdependent weights of the factors were calculated and the dependencies among the factors were considered. Dependence among the factors was determined by analyzing the impact of each factor on every other factor using pairwise comparisons. The dependencies between factors in each strategy are shown in Fig. 7. 


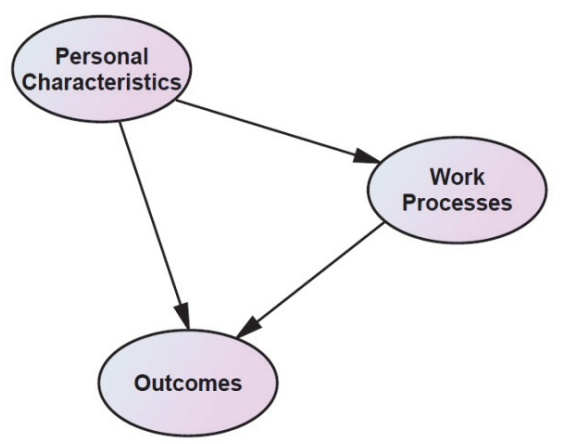

Fig. 7. Dependence among factors

These dependencies were determined by an expert team on the basis of a group study and following statements were obtained: (a) "personal characteristics" factor affect "work processes" and "outcomes" factor, (b) "work processes" factor affect "outcomes" factor.

Based on the dependencies presented in Fig. 7, expert team defined dependence among all factors via pairwise comparison matrices. For this purpose, three pairwise comparison matrices were formed for three strategies. The resulting relative importance weights of these matrices were calculated. These weights are listed in Table 4, separately for each strategy. "0" values presented in Table 4 mean that there is no dependence between two factors and the numerical values show the degree of relative impact between two factors.

Table 4

Degree of relative impact for factors in different strategies.

\begin{tabular}{llcccccccc}
\hline & \multicolumn{3}{l}{ Cost Leadership Strategy } & \multicolumn{3}{c}{ Focus Strategy } & \multicolumn{2}{c}{ Differentiation Strategy } \\
\cline { 2 - 9 } & $\mathrm{P}$ & $\mathrm{W}$ & $\mathrm{Q}$ & $\mathrm{P}$ & $\mathrm{W}$ & $\mathrm{Q}$ & $\mathrm{P}$ & $\mathrm{W}$ & $\mathrm{Q}$ \\
\hline $\mathrm{P}$ & 1 & 0.221 & 0.310 & 1 & 0.210 & 0.231 & 1 & 0.331 & 0.348 \\
$\mathrm{~W}$ & 0 & 0.779 & 0.280 & 0 & 0.789 & 0.251 & 0 & 0.669 & 0.333 \\
$\mathrm{Q}$ & 0 & 0 & 0.410 & 0 & 0 & 0.512 & 0 & 0 & 0.319 \\
\hline
\end{tabular}

Step 5: Using interdependent weights of the factors (Step 4) and local weights sub-factors, global weights for the sub-factors in each strategy are calculated in this step. Global sub-factor weights are computed by multiplying local weight of the sub-factor with the interdependent weight of the factor to which it belongs. Computed global weights for sub-factors are shown in Table 5.

Table 5

Computed local and global weights for factors and sub-factors for each strategy.

\begin{tabular}{llcccccc}
\hline & & \multicolumn{2}{c}{ Cost Leadership Strategy } & \multicolumn{2}{c}{ Focus Strategy } & \multicolumn{2}{c}{ Differentiation Strategy } \\
\cline { 3 - 8 } Factors & Sub-factors & Local Weights & $\begin{array}{c}\text { Global } \\
\text { Weights }\end{array}$ & $\begin{array}{c}\text { Local } \\
\text { Weights }\end{array}$ & $\begin{array}{c}\text { Global } \\
\text { Weights }\end{array}$ & $\begin{array}{c}\text { Local } \\
\text { Weights }\end{array}$ & $\begin{array}{c}\text { Global } \\
\text { Weights }\end{array}$ \\
\hline P & P1 & 0.484 & 0.043 & 0.134 & 0.018 & 0.049 & 0.023 \\
$(0.089)$ & P2 & 0.041 & 0.004 & 0.008 & 0.001 & 0.573 & 0.272 \\
$(0.136)$ & P3 & 0.183 & 0.016 & 0.470 & 0.064 & 0.266 & 0.126 \\
$(0.474)$ & P4 & 0.293 & 0.026 & 0.316 & 0.043 & 0.112 & 0.053 \\
\hline & W1 & 0.053 & 0.031 & 0.030 & 0.019 & 0.091 & 0.014 \\
W & W2 & 0.407 & 0.239 & 0.070 & 0.044 & 0.074 & 0.011 \\
$(0.588)$ & W3 & 0.076 & 0.045 & 0.360 & 0.225 & 0.222 & 0.033 \\
$(0.625)$ & W4 & 0.120 & 0.071 & 0.096 & 0.060 & 0.160 & 0.024 \\
$(0.149)$ & W5 & 0.063 & 0.037 & 0.054 & 0.034 & 0.054 & 0.008 \\
& W6 & 0.178 & 0.105 & 0.153 & 0.096 & 0.324 & 0.048 \\
\hline Q & Q1 & 0.104 & 0.061 & 0.238 & 0.149 & 0.074 & 0.011 \\
$(0.323)$ & Q2 & 0.598 & 0.193 & 0.308 & 0.073 & 0.045 & 0.017 \\
$(0.238)$ & Q3 & 0.094 & 0.030 & 0.183 & 0.044 & 0.520 & 0.196 \\
$(0.376)$ & O4 & 0.260 & 0.084 & 0.455 & 0.108 & 0.126 & 0.047 \\
\hline
\end{tabular}




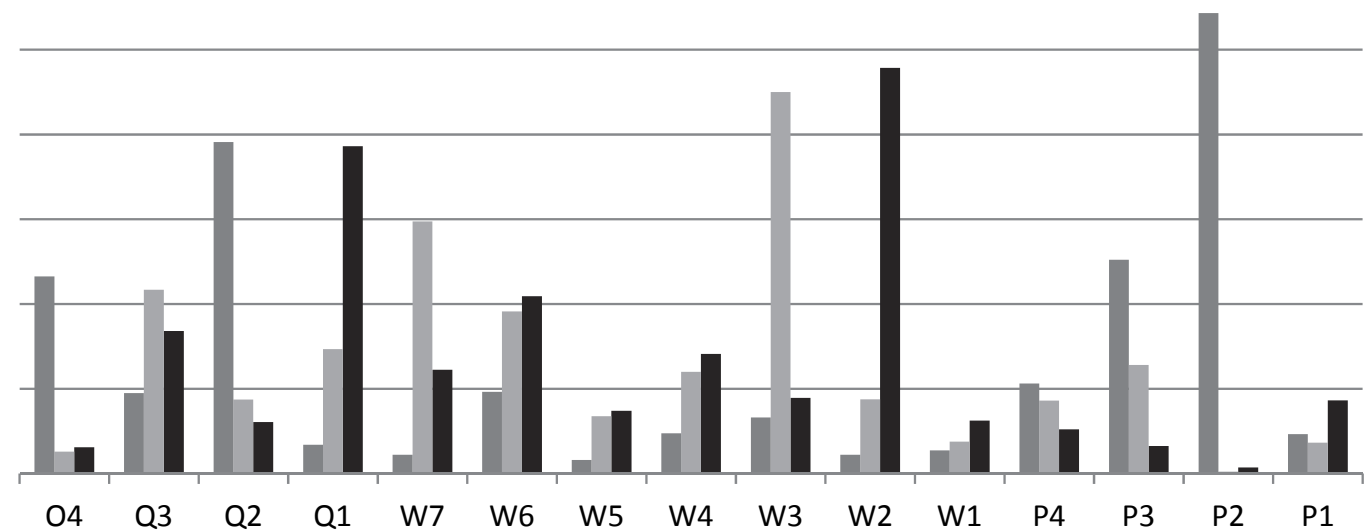

Fig. 8. Comparison of weights for sub-factors in different strategies

Step 6: In step 5 we calculate the importance of factors and sub-factors in three strategies. In many cases, organizations often do not use only one strategy, but they run a combination of different strategies. When we have different strategies, we can calculate the importance of each strategy. In this step, using pairwise comparison, the importance of each strategy calculated. These weights are listed in Table 6.

Table 6

Computed weights for strategies

\begin{tabular}{|c|c|c|c|c|}
\hline & Cost Leadership & Focus & Differentiation & Weights \\
\hline Cost Leadership & $(1,1,1)$ & $(2,5 / 2,3)$ & $(2,5 / 2,3)$ & 0.682 \\
\hline Focus & & $(1,1,1)$ & $(3 / 2,2,5 / 2)$ & 0.216 \\
\hline Differentiation & & & $(1,1,1)$ & 0.103 \\
\hline
\end{tabular}

Step 7: By multiplying global weight for sub-factors for each strategy and weights of strategies we can calculate global weight of sub-factors in mixed strategy. Results are listed in Table 7.

Table 7

Computed global weights for sub-factors for mixed strategy

\begin{tabular}{llll}
\hline Sub-factors & Global Weights & Sub-factors & Global Weights \\
\hline P1 & 0.036 & W5 & 0.033 \\
P2 & 0.031 & W6 & 0.097 \\
P3 & 0.038 & W7 & 0.075 \\
P4 & 0.033 & Q1 & 0.149 \\
W1 & 0.027 & Q2 & 0.050 \\
W2 & 0.174 & Q3 & 0.086 \\
W3 & 0.082 & O4 & 0.025 \\
W4 & 0.064 & & \\
\hline
\end{tabular}

Step 8,9: In this stage, performance of a sample employee determined through the proposed fuzzy ANP model by using the global weights of sub-factors (Table 7) and the linguistic measurement scale (Table 2). Performance computed for sample employee is shown in Table 8 . The sub-factors used to determine the performance, and their global weights $(\mathbf{g w})$ are shown in the first and second columns of Table 8 , respectively. The linguistic variables used in sub-factors evaluation and the scale values equivalent to these variables are shown in third and fourth columns respectively in Table 8 . The evaluation results obtained on the basis of sub-factors are shown in the last column of Table 8 and these evaluation results 
are summed to obtain performance of sample employee, which is shown in the last line of the table.

\section{Table 8}

Computed performance for a sample employee with the proposed fuzzy ANP model

\begin{tabular}{lllll}
\hline Sub-factors & Global Weights $(\mathrm{gw})$ & Linguistic variable & Scale value $(\mathrm{sv})$ & $\mathrm{gw} \times s v$ \\
\hline P1 & 0.036 & $\mathrm{H}$ & 0.75 & 0.027 \\
P2 & 0.031 & $\mathrm{H}$ & 0.75 & 0.023 \\
P3 & 0.038 & $\mathrm{H}$ & 0.75 & 0.028 \\
P4 & 0.033 & $\mathrm{M}$ & 0.5 & 0.016 \\
W1 & 0.027 & $\mathrm{M}$ & 0.5 & 0.013 \\
W2 & 0.174 & $\mathrm{M}$ & 0.5 & 0.087 \\
W3 & 0.082 & $\mathrm{~L}$ & 0.25 & 0.021 \\
W4 & 0.064 & $\mathrm{H}$ & 0.75 & 0.048 \\
W5 & 0.033 & $\mathrm{M}$ & 0.5 & 0.017 \\
W6 & 0.097 & VH & 1 & 0.097 \\
W7 & 0.075 & $\mathrm{H}$ & 0.75 & 0.056 \\
Q1 & 0.149 & VH & 1 & 0.149 \\
Q2 & 0.050 & VH & 1 & 0.050 \\
Q3 & 0.086 & $\mathrm{~L}$ & 0.25 & 0.021 \\
Q4 & 0.025 & $\mathrm{M}$ & 0.5 & 0.013 \\
\hline Performance score for sample employee & & & 0.667 \\
\hline
\end{tabular}

\section{Conclusions}

The most important factor which affects the success and realization of the strategy of the organizations is the human resource power that they gain. Some of the factors which determine the competitive power can be controlled by the organization whereas some others are not under the control of the organization; rather, they are dependent on the conditions constituting the close and distant environment of the sector they are active in. Hence, it is often difficult to try to examine or explain the competition concept under determined conditions or environments or to envisage and control it. That is why the competition concept includes complexity and vagueness in its nature. For this reason, it is not possible to sufficiently explain a concept - complex and vague in its nature - with a pairwise comparison (0-1) as in the classical logic. Therefore, the purpose of this study is to measure the performance of human resource by using ANP method within the framework of Porter's competitive strategy model.

The suggested fuzzy ANP model took into consideration that personal characteristics, work processes and outcomes have an impact on the performance of human resource. However, it was also taken into account that several correlations among the factors in the suggested model in each strategy could affect the performance. The main difference of this study from the others in the literature is that it showed that performance could be measured on the basis of these correlations in ANP model in different strategies.

This study aimed at measuring performance by taking into consideration the correlations between the factors in Porter's competitive strategies model. There may be some mutual interactions between the subfactors constituting these forces, depending on the structure and conditions of the sector the organization is active in. Such relation networks can be analyzed within the scope of future studies.

\section{References}

Anyaeche, C., Ighravwe, D., \& Asokeji, T. (2017). Project portfolio selection of banking services using COPRAS and Fuzzy-TOPSIS. Journal of Project Management, 2(2), 51-62.

Baird, L., \& Meshoulam, I. (1988). Managing two fits of strategic human resource management. Academy of Management review, 13(1), 116-128.

Buckley, J. J. (1985). Fuzzy hierarchical analysis. Fuzzy sets and systems, 17(3), 233-247.

Butler, J. E., Ferris G.R., \& Napier. N.K. (1991). Strategy and Human Resources Management. 
Cincinnati, OH.: South-Western. HRM: Contemporary issues in Europe, (eds.) Chris Brewster and Hilary Harris, 31-47. London and New York: Routledge.

Dağdeviren, M., \& Yüksel, İ. (2010). A fuzzy analytic network process (ANP) model for measurement of the sectoral competititon level (SCL). Expert systems with applications, 37(2), 1005-1014.

Druskat, V. U., \& Wolff, S. B. (1999). Effects and timing of developmental peer appraisals in selfmanaging work groups. Journal of Applied Psychology, 84(1), 58.

Chan, L. L., Shaffer, M. A., \& Snape, E. (2004). In search of sustained competitive advantage: the impact of organizational culture, competitive strategy and human resource management practices on firm performance. The International Journal of Human Resource Management, 15(1), 17-35.

Chang, D. Y. (1992). Extent analysis and synthetic decision, optimization techniques and applications (Vol. 352). Singapore: World Scientific.

Chang, D. Y. (1996). Applications of the extent analysis method on fuzzy AHP. European Journal of Operational Research, 95(3), 649-655.

Chen, J. K., \& Chen, I. S. (2010). A Pro-performance appraisal system for the university. Expert Systems with Applications, 37(3), 2108-2116.

Cheng, C. H., Yang, K. L., \& Hwang, C. L. (1999). Evaluating attack helicopters by AHP based on linguistic variable weight. European journal of operational research, 116(2), 423-435.

Cheng, C. H. (1997). Evaluating naval tactical missile systems by fuzzy AHP based on the grade value of membership function. European Journal of Operational Research, 96(2), 343-350.

Coens, T., \& Jenkins, M. (2000). Abolishing performance appraisals: Why they backfire and what to do instead. San Francisco: Berrett-Koehler Publishers.

Deng, H. (1999). Multicriteria analysis with fuzzy pairwise comparison. International journal of approximate reasoning, 21(3), 215-231.

Hambrick, D. C. (1983). Some tests of the effectiveness and functional attributes of Miles and Snow's strategic types. Academy of Management journal, 26(1), 5-26.

Huang, J. J., Tzeng, G. H., \& Ong, C. S. (2005). Multidimensional data in multidimensional scaling using the analytic network process. Pattern Recognition Letters, 26(6), 755-767.

Kahraman, C., Ertay, T., \& Büyüközkan, G. (2006). A fuzzy optimization model for QFD planning process using analytic network approach. European Journal of Operational Research, 171(2), 390411.

Kahraman, C., Ruan, D., \& Doğan, I. (2003). Fuzzy group decision-making for facility location selection. Information Sciences, 157, 135-153.

Karmaker, C \& Saha, M. (2015). Optimization of warehouse location through fuzzy multi-criteria decision making methods. Decision Science Letters, 4(3), 315-334.

Lengnick-Hall, C.A., \& Lengnick-Hall, M.L. (1988). Strategic human resource management: A review of the literature and a proposed typology. Academy of Management Review, 13(3), 454-470.

Leung, L. C., \& Cao, D. (2000). On consistency and ranking of alternatives in fuzzy AHP. European Journal of Operational Research, 124(1), 102-113.

Meade, L. M., \& Sarkis, J. (1999). Analyzing organizational project alternatives for agile manufacturing processes: an analytical network approach. International Journal of Production Research, 37(2), 241-261.

Mikhailov, L. (2004). A fuzzy approach to deriving priorities from interval pairwise comparison judgements. European Journal of Operational Research, 159(3), 687-704.

Miles, R. E., \& Snow, C. C. (1978). Organizational strategy, structure and process. New York: McGraw-Hill.

Miles, R., \& Snow, C. (1984). Designing strategic human resource systems. Organisational Dynamics, 
13(1), 36-52.

Ouchi, W. (1981). Theory Z. New York: Addison-Wesley.

Porter, M. E. (1980). Competitive strategy: Techniques for analyzing industries and competitors. New York: Free Press.

Saaty, T. L. (1996). Decision making with dependence and feedback: The analytic network process. Pittsburgh: RWS Publications.

Saaty, T. L., \& Takizawa, M. (1986). Dependence and independence: From linear hierarchies to nonlinear networks. European journal of operational research, 26(2), 229-237.

Sadatrasool, M., Bozorgi-Amiri, A \& Yousefi-Babadi, A. (2016). Project manager selection based on project manager competency model: PCA-MCDM Approach. Journal of Project Management, 1(1), 7-20.

Sadi-Nezhad, S. (2017). A state-of-art survey on project selection using MCDM techniques. Journal of Project Management, 2(1), 1-10.

Sandhya, S., \& Garg, R. (2016). Implementation of multi-criteria decision making approach for the team leader selection in IT sector. Journal of Project Management, 1(2), 67-75.

Soltannezhad Dizaji, M., Mahdavi Mazdeh, M. \& Makui, A. (2017). Performance evaluation and ranking of direct sales stores using BSC approach and fuzzy multiple attribute decision-making methods. Decision Science Letters, 7(2), 197-210.

Shyur, H. J. (2006). COTS evaluation using modified TOPSIS and ANP. Applied mathematics and computation, 177(1), 251-259.

Staw, B. M. (1980). Rationality and justification in organizational life. Greenwich, CT: JAI Press.

Tolga, E., Demircan, M. L., \& Kahraman, C. (2005). Operating system selection using fuzzy replacement analysis and analytic hierarchy process. International Journal of Production Economics, 97(1), 89-117.

Van Laarhoven, P. J. M., \& Pedrycz, W. (1983). A fuzzy extension of Saaty's priority theory. Fuzzy sets and Systems, 11(1-3), 229-241.

Wei, L. Q., \& Lau, C. M. (2005). Market orientation, HRM importance and competency: Determinants of strategic HRM in Chinese firms. The International Journal of Human Resource Management, 16(10), 1901-1918.

Wright, P.M., \& McMahan, G.C. (1992). Theoretical perspectives for strategic human resource management. Journal of Management, 18(2), 295-320.

Yüksel, İ., \& Dağdeviren, M. (2010). Using the fuzzy analytic network process (ANP) for Balanced Scorecard (BSC): A case study for a manufacturing firm. Expert Systems with Applications, 37(2), 1270-1278.

Zadeh, L. A. (1965). Fuzzy sets. Information and Control, 8(3), 338-352.

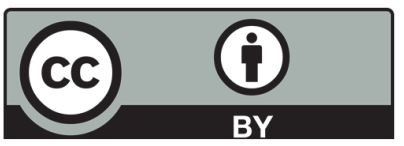

(C) 2018 by the authors; licensee Growing Science, Canada. This is an open access article distributed under the terms and conditions of the Creative Commons Attribution (CC-BY) license (http://creativecommons.org/licenses/by/4.0/). 